\begin{tabular}{|l|l|l|}
\hline \multicolumn{2}{|c|}{ PublisherInfo } \\
\hline \hline PublisherName & $:$ & BioMed Central \\
\hline \hline PublisherLocation & $:$ & London \\
\hline \hline PublisherImprintName & $:$ & BioMed Central \\
\hline \hline
\end{tabular}

\title{
VEGFR-3 and VEGF-C in angiogenesis
}

\begin{tabular}{|l|l|l||}
\hline \multicolumn{2}{|c||}{ ArticleInfo } \\
\hline \hline ArticleID & $:$ & 3600 \\
\hline \hline ArticleDOI & $:$ & $10.1186 /$ bcr-1999-66578 \\
\hline \hline ArticleCitationID & $:$ & 66578 \\
\hline \hline ArticleSequenceNumber & $:$ & 20 \\
\hline \hline ArticleCategory & $:$ & Paper Report \\
\hline ArticleFirstPage & $:$ & 1 \\
\hline \hline ArticleLastPage & $:$ & 4 \\
\hline \hline & & RegistrationDate : 1999-5-21 \\
\hline ArticleHistory & $:$ & OnlineDate \\
\hline \hline ArticleCopyright & $:$ & Current Science Ltd1999-5-21 \\
\hline \hline ArticleGrants & $:$ & \\
\hline \hline ArticleContext & $:$ & 1305811 \\
\hline \hline
\end{tabular}




\section{Keywords}

breast, angiogenesis, lymphangiogenesis, VEGFR-3, VEGF-C

\section{Introduction}

While active angiogenesis is known to be a prerequisite for tumor growth beyond a few $\mathrm{mm}^{3}$ in size, lymphangiogenesis in normal or pathological adult tissues, including malignant tumors has not been reported. If lymphangiogenesis takes place during cancer progression, cancers with active lymphangiogenesis could be predisposed to metastatic spread via the lymphatic system and thus to poor survival.

VEGFR-3 is a receptor tyrosine kinase that is similar to the two VEGF receptors in structure but does not bind VEGF, placenta growth factor, or VEGF-B. VEGFR-3 is initially expressed in all embryonic endothelia, but its expression in the blood vessel endothelium decreases during development, and it becomes largely restricted to the lymphatic endothelium in adult tissues.

The two known ligands of VEGFR-3 have a high degree of homology to VEGF and have been named as VEGF-C17 and VEGF-D18. Experiments in transgenic mice have shown that VEGF-C is a growth factor for the developing lymphatic vessels and expression of VEGF-C mRNA has also been detected in malignant human tumors.

\section{Aims}

The aim was to determine whether lymphangiogenesis takes place during cancer progression, and if so, whether VEGF-C has a role.

\section{Comments}

This study demonstrates that VEGFR-3 may play an important role in angiogenesis with upregulation occurring in proliferating vessels adjacent to tumors, possibly as a result of paracrine secretion of its ligand, VEGF-C, by neoplastic cells. Lymphangiogenesis, however, does not appear to 
have a major role in breast cancer and other factors, such as lymphatic permeability, are probably more important in metastasis via this route.

\section{Methods}

The study used freshly frozen breast tissue from patients with ductal carcinoma $(n=6)$, lobular carcinoma $(n=6)$, intraductal carcinoma $(n=8)$, fibroadenoma $(n=4)$, and histologically normal breast tissue $(n=12)$.

Immunohistochemistry was performed on cryosections using a mouse monoclonal antibody raised against human VEGFR-3. Double staining with the blood vascular endothelial marker PAL-E and VEGFR-3 antibodies was used to differentiate immunohistochemical staining of lymphatic and blood vessels in two intraductal carcinomas. In order to study if the endothelial cells in VEGFR-3 positive necklace vessels in intraductal carcinoma were undergoing angiogenesis, two intraductal samples were chosen for double staining for the nuclear proliferation markers Ki-67 and VEGFR-3.

Polyclonal antibodies were produced in rabbits against a synthetic peptide corresponding to the amino acid residues 2-18 of the N-terminus of mature secreted human VEGF-C (residues 104-120 of the VEGF-C pre-propeptide) and were used to stain the intraductal and the invasive carcinomas.

\section{Results}

Immunohistochemical staining of VEGFR-3 in normal breast tissue showed weak staining in capillaries. Most of such vessels were strongly stained for PAL-E and for the basal lamina component, collagen XVIII, suggesting that VEGFR-3 was expressed weakly in the blood vessels of normal breast tissue. VEGFR-3 positive vessels were also uniformly found in benign fibroadenomas.

In intraductal carcinomas, VEGFR-3 positive vessels formed arch-like structures around the affected ducts. This necklace pattern was also observed in staining of adjacent sections for PAL-E, suggesting that VEGFR-3 expression was enhanced in capillary endothelium. The small vessels close to the intraductal carcinomas expressed VEGFR-3 and the basal lamina proteins but stained more weakly for smooth muscle actin, suggesting that they are incompletely covered by pericytes/smooth muscle cells. In contrast, larger blood vessels at some distance from the intraductal lesions were in general negative for VEGFR-3. Dual labelling immunohistochemistry confirmed coexpression of VEGFR-3 and PAL-E. The invasive breast carcinomas when compared with normal breast tissue had a significantly higher intratumoral VEGFR-3 positive vessel density $(P<0.0001$, the Mann-Whitney test).

Double staining using antibodies against Ki-67 and VEGFR-3 showed several endothelial cell nucleae were Ki-67 positive of the necklace vessels but not in vessels some distance away. 
VEGF-C staining was identified in all the intraductal carcinomas and in most of the invasive carcinomas.

\section{Discussion}

VEGFR-3, which has been described to be a predominantly lymphatic endothelial marker in most adult tissues, is also very weakly expressed in the capillary endothelium of normal breast tissue. The number of VEGFR-3 positive vessels is elevated in breast cancer. Part of the VEGFR-3 positive vessels are angiogenic blood vessels with up-regulated expression of VEGFR-3 in the endothelial cells. However, a part of the VEGFR-3 positive structures appear to be lymphatic vessels, although there was no evidence that lymphangiogenesis occurs in breast cancers.

The presence of VEGF-C in intraductal carcinoma cells as well as the VEGFR-3 positive capillaries surrounding the affected ducts suggest that VEGF-C secreted by the cancer cells acts predominantly as an angiogenic growth factor, but it could also affect the lymphatic vessels during tumor metastasis into the axillary lymph nodes.

\section{References}

1. Valtola R, Salven P, Heikkila P, Taipale J, Joensuu H, Rehn M, Pihlajaniemi T, Weich H, deWaal R, Alitalo K: VEGFR-3 and its ligand VEGF-C are associated with angiogenesis in breast cancer. Am J Pathol. 1999, 154: 1381-1390. 